\title{
Mortality after death of spouse in relation to duration of bereavement in Finland
}

\author{
Pekka Martikainen, Tapani Valkonen
}

\begin{abstract}
Study objectives - (1) To assess the extent to which death of a spouse causes excess mortality by controlling for the effects of confounding and other sources of bias. Three possible sources of bias are considered: accidents common to spouses, common socioeconomic environment, and common lifestyles. (2) To assess the duration specific effects of death of a spouse on mortality.

Design and setting - Prospective study of mortality in Finland among all 35-84 year old married Finnish men and women (1 580000 people). Baseline sociodemographic measurement from the $\mathbf{1 9 8 5}$ census records. Follow up by computerised record linkage to death certificate registers for the period 1986-91 (about 116000 deaths, of which almost 10000 among the bereaved) using personal identification codes.

Results - (1) After controlling for confounding effects, excess mortality was $17 \%$ in men and $6 \%$ in women. (2) Excess mortality was higher for short durations than long durations of bereavement. (3) Excess mortality after bereavement was higher in men than women.

Conclusions - Controlling for confounding does not seem to have a crucial modifying effect on the relationship between spousal bereavement and mortality. It seems that death of a spouse has a causal effect on mortality. However, although spousal bereavement is a major stressful life event, this causal effect seems to be relatively small and short lived.
\end{abstract}

(F Epidemiol Community Health 1966;50:264-268)

Besides being relevant to the care of widowed people, study of the health effects of spousal bereavement offers a more general opportunity to evaluate the effects of emotional stress and loss of social support on mortality. Although there are some differences in details, most studies indicate that mortality rates after the death of a spouse are higher than in married persons for both men and women. ${ }^{1-4}$ This excess mortality may be due to the causal effects of the loss of a spouse, but bias or confounding could also be involved. Three main artefact explanations can be proposed:

- A common accident involving both spouses. These include motor vehicle accidents, fires, or drowning. Many of these accidents lead to the death of both spouses on the same day, but in some cases the death of the other spouse may be delayed by several days or weeks, thus creating an impression that bereavement caused the death.

- Homogamy - that is, the tendency of similar persons to marry. If this homogamous tendency is based on predispositon to illness (for example, the sick or those with poor health potential or substance abusers marry each other) the times of death of spouses will cluster and create an impression of bereavement causing death. ${ }^{135}$

- A common unfavourable environment shared by the spouses. ${ }^{135}$ It is reasonable to assume that couples share many aspects of their daily life. Part of this "comon environment" may be hazardous to health. For example, spouses may share substandard housing or an unhealthy diet. Spouses' deaths may thus be correlated and be from causes that have a similar aetiology.

There are several assumptions about how the loss of a spouse may cause excess mortality. It has been suggested that the mechanisms involved include (1) emotional stress and grief, ${ }^{3}$ (2) loss of social support, ${ }^{6}$ or (3) loss of material or task support. ${ }^{16}$ Before analysing these mechanisms it is necessary to establish the extent to which the observed excess mortality is in fact due to the causal effects of bereavement. This paper aims to assess the extent to which loss of a spouse causes excess mortality by eliminating, as adequately as possible, the three artefactual explanations proposed. At this stage we will not be analysing the mechanisms underlying the possible causal effect of loss of spouse on mortality. Furthermore, we will examine the effects of the death of a spouse on mortality in relation to duration of bereavement.

Our data set is based on linked census and death records and provides a good opportunity to tackle these research questions. The data cover a large population and allow more accurate control of confounding than has been the case in previous studies.

\section{Data}

The study is based on the 1985 census records in Finland linked with all deaths during the period 1986-91. The linking together of the data sets has been carried out by Statistics Finland by means of personal identification codes. ${ }^{7}$ This analysis is concerned with married men and women aged between 35-84 years 
in the 1985 census. The study population is followed for the subsequent five years after the death of a spouse. Death of the reference person is followed for six years. About $0.3 \%$ of deaths could not be matched to a census record. The error caused by divorce after the census is small; in the late 1980s the divorce rate among 35-44 and 50-64 year old married women was around 1.5 and $0.5 \%$, respectively. ${ }^{8}$

There were about 820000 married men and 760000 married women at the beginning of the follow up. The number of deaths was about 116000 , of which almost 10000 were among the widowed. Altogether 22294 men and 61686 women were widowed during the follow up period. Deaths in 1986 were classified according to the 8th revision of the International Classification of Diseases and Deaths (ICD), and deaths in 1987-91 according to the 9th revision.

\section{DURATION OF BEREAVEMENT}

Duration of bereavement is divided into nine categories. The classification reflects the importance of analysing mortality shortly after bereavement, when the acute srress is believed to be most severe. Spouses who died on the same day were not considered as widowed because in most cases it was impossible to determine which spouse was widowed (that is, died later). Information on the spouse's date of death was obtained by linking all married persons' death records to those of their surviving spouse of 1985 .

\section{CONTROL VARIABLES}

In each age group widowed persons were on average somewhat older than married persons. If wide age groups are used for age standardisation, widowed persons will have an artificially high excess mortality. ${ }^{5}$ To avoid such bias we controlled for age at the start of the follow up in one year intervals. Our calculations showed that for total mortality the upward bias in death rates among men was $10 \%$ when five year as opposed to one year age groups were used for standardisation. The bias is $40 \%$ when 10 year age groups are utilised. The corresponding biases among women were 20 and $90 \%$.

Characteristics of the socioeconomic environment - socioeconomic status of the household, region of residence, language group, and size of the household - may have an effect on mortality. ${ }^{9-10}$ As these variables are common attributes of both spouses or characterise the household, they may be confounding variables generating excess mortality among the bereaved.

Two measures of socioeconomic status are used: housing tenure and family disposable income. Housing tenure was divided into two categories: (1) living in owner occupied housing and (2) living in rented housing or information on housing tenure not available.

Family disposable income comprised all income earned by the family members, including wages, pensions, maternity allowances, child benefits, etc. Taxes were deducted. The information on different sources of income come from the tax return forms held in the registers of the National Board of Taxation and the registers of the Social Insurance Institution. The measure of family disposable income was divided into quartiles. Persons with no information on family disposable income $(0.3 \%$ of the total study population) were slotted into the lowest income category.

The first four groups of size of household consisted of persons who live in households that are from one to four in size. The fifth category included all those who lived in a household with five or more persons.

The six category classification of region of residence was based on the 12 provinces of Finland. The classification distinguishes eastern and western provinces and separates the poorer northern provinces from the better off provinces of southern Finland. Language group was divided into two categories: Finnish speakers $(93 \%)$ and others $(7 \%)$, of whom most were Swedish speakers.

All variables describing common socioeconomic environment were measured at the individual level. However, with the exception of language, all these characteristics were shared by the household. This guaranteed, as far as possible, that these characteristics were in fact "common".

\section{Methods}

The deaths and exposures were cross tabulated according to the variables included in the analysis. Poisson regression analysis was used in the analysis of the cross tabulations. ${ }^{11}$ The GLIM statistical package was used in fitting the models. ${ }^{12}$ The parameters of the Poisson models are presented as relative mortality rates. The first category of each explanatory variable was taken as a reference group, with a relative rate of one.

In addition to age, period (one year periods) was controlled for in all models. Controlling for period is necessary because the study cohort ages during the follow up period. Ageing creates upward bias in the relative mortality rates at longer durations of bereavement. In a six year cohort follow up, deaths at long durations of bereavement all take place during the latter part of the follow up period among persons who are on average somewhat older than the non-bereaved reference group.

\section{Results}

EXCESS MORTALITY IN RELATION TO DURATION OF BEREAVEMENT

Excess mortality among all bereaved men was $21 \%$. In the first week, the excess was more than $50 \%$, but it slowly dropped to a level of around $20 \%$ after six months of bereavement. The excess mortality among all bereaved women was $9 \%$, ranging from the early excess of almost $50 \%$ to less than $10 \%$ at longer durations of bereavement (Figure). 


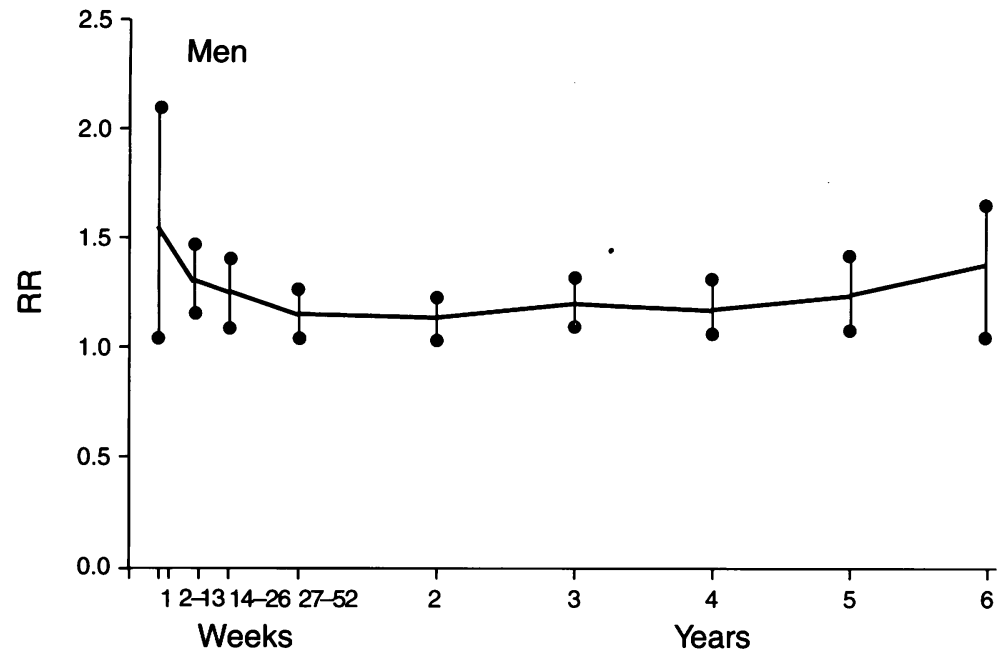

Duration of bereavement

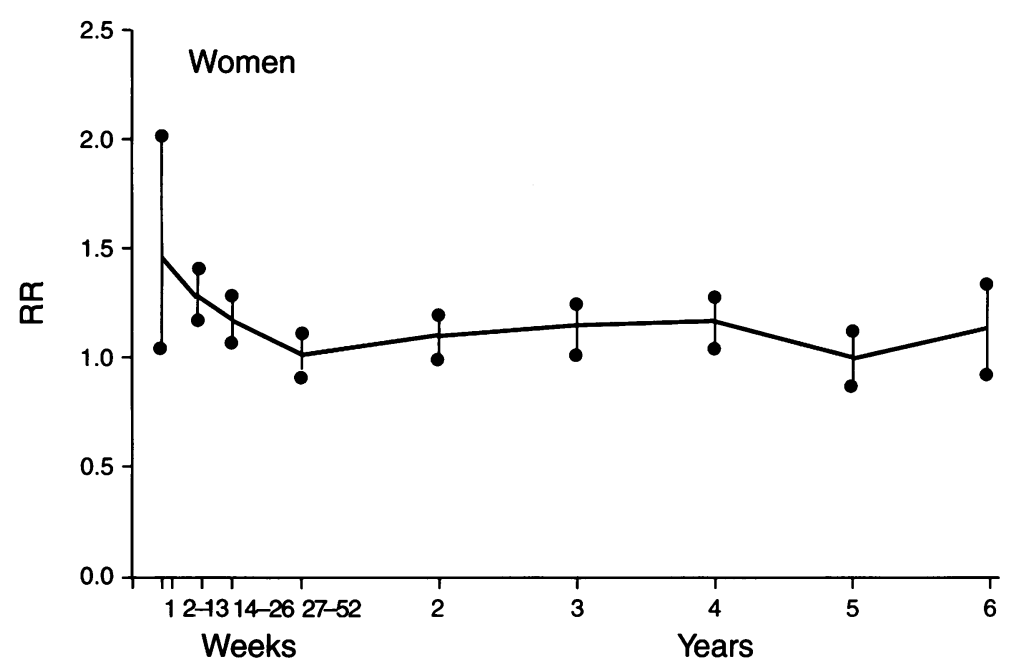

Duration of bereavement

Relative age and period standardised mortality rates $(R R)$ and $95 \%$ confidence intervals in relation to duration of bereavement (not bereaved $=1 \cdot 00$ ) in 35-84 year old Finnish men and women married at the beginning of the follow up in 1985.

THE CONTRIBUTION OF COMMON ACCIDENTS

Excess mortality during the first six months of bereavement was very high among both men and women for causes related to accidents and violence (table 1); among men the relative mortality rate was about 3 and among women

Table 1 Relative age and period standardised mortality rates in relation to duration of bereavement (not bereaved =1.00) from accidents and violence (E800-E999) and all causes in 35-84 year old Finnish men and women married at the beginning of the follow up in 1985.

\begin{tabular}{lllll}
\hline & $\begin{array}{l}\text { Accidents and } \\
\text { violence }\end{array}$ & $\begin{array}{l}\text { "Cleaned"* accidents } \\
\text { and violence }\end{array}$ & $\begin{array}{l}\text { All } \\
\text { causes }\end{array}$ & $\begin{array}{l}\text { "Cleaned" } \\
\text { all causes }\end{array}$ \\
\hline Men & 1.00 & 1.00 & 1.00 & 1.00 \\
Not bereaved & $2.84 \dagger$ & $2.53 \dagger$ & $1.30 \dagger$ & $1.29 \dagger$ \\
Up to 6 months & $1.85 \dagger$ & $1.82 \dagger$ & $1.19 \dagger$ & $1.19 \dagger$ \\
$\begin{array}{l}\text { 6+ months } \\
\text { All bereaved }\end{array}$ & $2.01 \dagger$ & $1.94 \dagger$ & $1.21 \dagger$ & $1.20 \dagger$ \\
Women & & & & \\
Not bereaved & 1.00 & 1.00 & 1.00 & 1.00 \\
Up to 6 months & $2.42 \dagger$ & $2.32 \dagger$ & $1.22 \dagger$ & $1.22 \dagger$ \\
6+ months & $1.38 \dagger$ & $1.37 \dagger$ & $1.07 \dagger$ & $1.07 \dagger$ \\
All bereaved & $1.54 \dagger$ & $1.51 \dagger$ & $1.09 \dagger$ & $1.09 \dagger$ \\
\hline
\end{tabular}

* "Cleaned" - deaths not due to violent or accidental causes common to both spouses. $\dagger-R R$ different from 1.00 at the $95 \%$ confidence level. it was $2 \cdot 4$. The very high excess mortality during the first six months could be partially attributable to a common event, for example a traffic accident which causes first the death of one spouse and then later the death of the other spouse. In such a case, the death of the spouse dying later is not causally related to widowhood. The extent to which such cases account for the high overall excess mortality can be assessed by removing from the analysis all cases where both spouses had the same accidental and violent cause of death. The similarity was assessed at the 3-digit level of the ICD. At longer durations of bereavement, this procedure may somewhat "overclean" the relative mortality rates, but it is appropriate at shorter durations when the problem of common accidents is most relevant.

Common accidents and violence accounted for about 11 and $4 \%$ of the accidental and violent causes of death of widowed men and women respectively in the first six months of widowhood (table 1).

Among men the 2.84 fold excess of accidental and violent mortality in the first six months after widowhood was reduced to 2.53 when common accidents and violent deaths were removed from the data. The corresponding decline among women was from $2 \cdot 42$ to $2 \cdot 32$. The exclusion of common accidents and violence from analyses had only a marginal effect on excess mortality rates at longer durations of widowhood. The overall excess mortality from all causes of death is only marginally affected by common accidents.

CONTROLLING FOR THE EFFECTS OF COMMON MARITAL ENVIRONMENT AND HOMOGAMY

It is reasonable to assume that married couples share many aspects of their daily life. Furthermore, persons with similar characteristics or life styles before marriage may be more likely to marry. If any of these characteristics are detrimental to health, both spouses run a risk of early death.

Explanations for high mortality among widowed persons that are based on common marital environment or homogamy imply that spouses are similar in respect to certain health related characteristics. These characteristics may refer to either (1) common socioeconomic environment (for example, housing) or (2) common life styles (for example, use of tobacco and alcohol).

\section{COMMON SOCIOECONOMIC ENVIRONMENT}

Table 2 shows the relative mortality rates for all causes except common accidents and violence ("cleaned" all causes) standardised for age, period, and common environment before bereavement. Controlling for housing tenure and family disposable income had only a minor effect on relative mortality rates. The reduction in relative rates obtained by the statistical controls was in the region of $5-15 \%$, depending on the duration of bereavement. The reduction in relative rates was larger at longer durations 
Table 2 Relative mortality rates from "cleaned"* all causes in relation to duration of bereavement (not bereaved=1.00): standardizing for background factors in 35-84 year old Finnish men and women married at the beginning of the follow up in 1985.

\begin{tabular}{llllll}
\hline & Age + year+tbt & +hou+inc & +hhs & +reg & +lan \\
\hline Men & & & & & \\
Not bereaved & 1.00 & 1.00 & 1.00 & 1.00 & 1.00 \\
Up to 6 months & 1.30 & 1.27 & 1.27 & 1.27 & 1.27 \\
6+ months & 1.19 & 1.16 & 1.17 & 1.16 & 1.16 \\
All bereaved & 1.20 & 1.18 & 1.18 & 1.18 & 1.18 \\
Women & & & & & \\
Not bereaved & 1.00 & 1.00 & 1.00 & 1.00 & 1.00 \\
Up to 6 months & 1.22 & 1.21 & 1.21 & 1.21 & 1.21 \\
6+ months & 1.07 & 1.06 & 1.06 & 1.06 & 1.06 \\
All bereaved & 1.09 & 1.08 & 1.08 & 1.08 & 1.08
\end{tabular}

* "Cleaned" - deaths not due to violent or accidental causes common to both spouses.

† The manner of indicating the terms included in the model or added to the model is similar to that used in the GLIM statistical package. When referring to a model with several explanatory variables the names of the variables are separated by a plus sign. When a term is added to a model it is preceded by a plus sign.

age = age; year = year of follow up; tb = time after bereavement; hou = housing tenure; inc $=$ family disposable income; hhs =household size; reg = region of residence; lan=language group.

Table 3 Relative age, period, housing tenure, and family income standardised (one year age groups) mortality rates in relation to own and spouse's type of cause of death (not bereaved =1.00) in 35-84 year old Finnish men and women married at the beginning of the follow up in 1985.

\begin{tabular}{|c|c|c|c|}
\hline \multirow[t]{2}{*}{ Spouse's type of cause of death } & \multicolumn{3}{|c|}{ Own type of cause of death } \\
\hline & $\begin{array}{l}\text { "Risk-taking" } \\
\text { causes* }\end{array}$ & $\begin{array}{l}\text { Non-"risk taking" } \\
\text { causes }\end{array}$ & $\begin{array}{l}\text { "Cleaned" } † \\
\text { all causes }\end{array}$ \\
\hline \multicolumn{4}{|l|}{ Men } \\
\hline Spouse alive & $1 \cdot 00$ & $1 \cdot 00$ & $1 \cdot 00$ \\
\hline Non-“risk taking" causes & $1 \cdot 325$ & $1 \cdot 145$ & $1 \cdot 17 \S$ \\
\hline "Risk taking" causes & $2 \cdot 02 \oint$ & $1 \cdot 22 \oint$ & $1 \cdot 325$ \\
\hline All bereaved & $1 \cdot 37 \S$ & $1 \cdot 15 \S$ & $1 \cdot 180$ \\
\hline \multicolumn{4}{|l|}{ Women } \\
\hline Spouse alive & 1.00 & 1.00 & 1.00 \\
\hline Non-"risk taking" causes & $1 \cdot 320$ & 1.045 & 1.060 \\
\hline "Risk taking" causes & $1.90 \$$ & $1 \cdot 14 \S$ & $1 \cdot 19 \oint$ \\
\hline All bereaved & $1 \cdot 42 \sqrt{2}$ & $1 \cdot 06 \$$ & $1 \cdot 08 \S$ \\
\hline
\end{tabular}

* "Risk taking" causes - causes of death that are due to accidents and violence or are strongly related to the use of alcohol and tobacco: alcoholic psychosis (ICD 291); alcoholism (ICD 303); alcoholic liver diseases and cirrhosis of the liver (ICD 5710-5713); alcoholic diseases of the pancreas (5770D-F, 5771C,D); cancer of the mouth and pharynx (ICD 140-149); cancer of the oesophagus (ICD 150); cancer of the larynx (ICD 161); lung cancer (ICD 162); chronic obstructive pulmonary disease (ICD 490-492); accidents and violence (E800-E999).

$t$ "Cleaned" all causes - all causes of death except those violent or accidental causes of death that are common to both spouses.

$\ddagger$ Non- "risk taking" causes - all causes of death except "risk taking" causes.

$\$-$ RR different from 1.00 at the $95 \%$ confidence level.

of widowhood. Controlling for household size, region, and language group had no effect on relative mortality rates.

\section{COMMON LIFE STYLES}

Spouses' deaths may be related to each other if persons who have poor health or persons who engage in health damaging behaviour have a tendency to marry each other or if spouses' habits converge during marriage.

In the absence of data on the life styles of the persons covered by the study, we could not directly analyse the possible contribution of common life styles on the excess mortality of the bereaved. Instead we attempted to assess the effect of common life style indirectly by using data on own and spouse's cause of death. A distinction was made between two types of causes of death: (1) "risk taking" causes are related to hazardous life styles, including all accidental and violent causes and causes strongly related to alcohol and tobacco use; (2) all other causes (see footnotes in table 3 for more details). "Risk taking" causes comprise about $20 \%$ of all deaths among widowed men and $10 \%$ of those in widowed women.

If the spouse died of a "risk taking" cause, mortality of the widowed husband or wife was higher for both "risk taking" and other causes of death than if the spouse had died of other causes (table 3). Relatively high mortality after the spouse's death of a "risk taking" cause might have been due to either the other spouse sharing the same "risk taking" characteristics or to the spouse dying unexpectedly (accidents and violence). However, as far as assessing the effects of common life styles was concerned, the more important observation was that excess mortality after widowhood remained even if the first spouse died of other causes than "risk taking" causes. For "cleaned" all causes, the excess mortality after bereavement from non"risk taking" causes was only slightly lower than that observed for all bereaved - $17 \%$ among men and $6 \%$ among women.

\section{Discussion}

This study has shown that there is excess mortality among both men and women after a spouse dies. The age standardised excess mortality in men was almost $30 \%$ during the first six months and about $20 \%$ thereafter; the corresponding figures for women were 20 and less than $10 \%$. During the first week of bereavement, excess mortality was around $50 \%$ in both men and women.

Three possible confounding effects or sources of bias were analysed: deaths from accidents involving both spouses', .common socioeconomic environment, and common life style. Common accidents slightly increased the excess mortality of widowed persons from all accidental and violent causes of death during the first six months of bereavement, but had a negligible effect on total mortality.

Although spouses share a common socioeconomic environment or life style it seems that this has only a limited effect. Controls for housing tenure and income, household size, region of residence, and language group reduced the excess mortality of the bereaved by only about $10 \%$. Analysis of both spouses' causes of death, classified according to a life style dimension of disease aetiology, also provided only limited evidence for a non-causal explanation of the relationship between bereavement and mortality. Although spouses' deaths are correlated, it seemed that the contribution of such deaths to overall excess mortality was small. However, the controls introduced here may not control sufficiently for exposure to common socioeconomic conditions and common life style.

Nevertheless, after controlling for age and period in single years, excluding common accidents and violence, and standardising as adequately as possible for common socioeconomic environment and life styles, both men and women experienced excess mortality after spousal bereavement. It appears then that this excess mortality is caused by death of a 
spouse. The mechanisms leading from bereavement to excess mortality are largely unknown. However, the pattern of excess mortality in relation to duration of bereavement indicates that stress and grief have a short term effect, while the effects of loss of social, material, and task support may dominate at longer durations of bereavement.

Although the details of earlier research results vary, the findings of this study are in broad agreement with most other follow up studies of adequate size..$^{1-413-19}$ However, some studies have reported higher excess mortality at very short durations. ${ }^{3-4}$ The results obtained from the Finnish record linkage data are in some respects more accurate than those obtained before; the data cover a large population and allow more accurate control for confounding than has been possible in previous studies. Furthermore, the effects of the duration of bereavement have been analysed in more detail.

In summary, a causal effect of death of a spouse on mortality seems to exist. However, although spousal bereavement is a major stressful life event, this causal effect seems to be relatively small and short lived. With a $17 \%$ excess mortality among bereaved men and a $6 \%$ excess among bereaved women, excess deaths caused by bereavement account for only $0 \cdot 8 \%$ of all deaths in the population covered by this study.

The authors thank Statistics Finland for permission to use the data (TK-53-69-87). The work has been supported by the Social Science Research Council of the Academy of Finland.
1 Young M, Benjamin B, Walls C. The mortality of widowers. Lancet 1963; ii:454-456.

2 Mellström D, Nilsson A, Odén A, Rundgren Å, Svanborg A. Mortality among the widowed in Sweden. Scand $\mathcal{F}$ Soc Med 1982;10:33-41.

3 Kaprio J, Koskenvuo M, Rita H. Mortality after bereavement: A prospective study of 95,647 widowed perreavement: A prospective study of 95,647

4 Jones DR, Goldblatt PO. Cause of death in widow(er)s and spouses. F Biosoc Sci 1987;19:107-121.

5 Susser M. Widowhood: A situational life stress or a stressfu life event? Am ₹ Public Health 1981;71:793-795.

6 Bowling A. Mortality after bereavement: A review of the literature on survival periods and factor affecting survival Soc Sci Med 1987;24:117-24.

7 Valkonen T, Martelin T, Rimpelä A, Notkola V, Savela S. Socio-economic mortality differences in Finland 1981-90. Statistics Finland. Population 1993:1.

8 Statistics Finland. Statistical Yearbook of Finland 1993. Statistics Finland, 1993.

9 Valkonen T. Psychosocial stress and sociodemographic differentials in mortality from ischaemic heart disease in Finland. Acta Med Scand 1982;660(suppl):152-64.

10 Martikainen P. Mortality and socio-economic status among Finnish women. Population Studies 1995;49:71-90.

11 Aitkin $M$, Clayton D. The fitting of exponential, Weibul and extreme value distributions to complex censored survival data using GLIM. Applied Statistics 1980;29:156-63.

12 Payne C ed. The GLIM system. Release 3.77 Manual. Oxford: Numerical Algorithms Group Ltd, 1985.

13 Parkes CM, Benjamin B, Fitzgerald RG. Broken heart: A statistical study of increased mortality among widowers. BMF 1969;1:740-43.

14 Jones DR, Goldblatt PO, Leon DA. Bereavement and cancer: Some data on deaths of spouses from the longitudinal study of Office of Population Censuses and Surveys. BMF study of Office of

15 Jones DR, Goldblatt PO. Cancer mortality following widow(er)hood: Some further results from the Office of Population Censuses and Surveys Longitudinal Study. Stress Medicine 1986;2:129-40.

16 Jones DR. Heart disease mortality following widowhood Some results from the OPCS longitudinal study. $\mathcal{f}$ Psychosom Res 1987;31:325-33.

17 Helsing KJ, Szklo M. Mortality and bereavement. $A m$ Epidemiol 1981;114:41-52.

18 Helsing KJ, Szklo M, Comstock GW. Factors Associated with Mortality after Widowhood. Am f Public Health 1981; 71:802-9.

19 Helsing KJ, Comstock GW, Szklo M. Causes of death in widowed population. Am f Epidemiol 1982;116:524-32. 